\title{
Validation of the Developed Zero-Order Infrared Spectrophotometry Method for Qualitative and Quantitative Analyses of Tranexamic Acid in Marketed Tablets
}

\author{
Nerdy Nerdy ${ }^{1, * \mathbb{D}}$, Linda Margata ${ }^{1}$, Bunga Mari Sembiring ${ }^{2}$, Selamat Ginting ${ }^{2}$, Effendy De Lux Putra ${ }^{3}$ and \\ Tedy Kurniawan Bakri ${ }^{4}$
}

\section{check for}

updates

Citation: Nerdy, N.; Margata, L.; Sembiring, B.M.; Ginting, S.; Putra, E.D.L.; Bakri, T.K. Validation of the Developed Zero-Order Infrared Spectrophotometry Method for Qualitative and Quantitative Analyses of Tranexamic Acid in Marketed Tablets. Molecules 2021, 26, 6985. https://doi.org/10.3390/ molecules 26226985

Academic Editor: Andrzej Grzechnik

Received: 30 September 2021

Accepted: 16 November 2021

Published: 19 November 2021

Publisher's Note: MDPI stays neutra with regard to jurisdictional claims in published maps and institutional affiliations.

Copyright: (C) 2021 by the authors. Licensee MDPI, Basel, Switzerland. This article is an open access article distributed under the terms and conditions of the Creative Commons Attribution (CC BY) license (https:/ / creativecommons.org/licenses/by/ $4.0 /)$.
1 Department of Pharmacy, Faculty of Pharmacy, Institut Kesehatan Deli Husada Deli Tua, Deli Tua Timur, Deli Tua, Deli Serdang 20355, Indonesia; lindamargata@hotmail.com

2 Department of Public Health, Faculty of Public Health, Institut Kesehatan Deli Husada Deli Tua, Deli Tua Timur, Deli Tua, Deli Serdang 20355, Indonesia; bungamerisembiring@gmail.com (B.M.S.); selamatginting18@gmail.com (S.G.)

3 Department of Pharmacy, Faculty of Pharmacy, Universitas Sumatera Utara, Padang Bulan, Medan Baru, Medan 20155, Indonesia; effendy@usu.ac.id

4 Department of Pharmacy, Faculty of Mathematics and Natural Sciences, Universitas Syiah Kuala, Kopelma Darussalam, Syiah Kuala, Banda Aceh 23111, Indonesia; tedykbakri@unsyiah.ac.id

* Correspondence: nerdy190690@gmail.com; Fax: +62-61-7030083

Abstract: (1) Background: The functional groups present in tranexamic acid allow direct infrared detection analysis. This study aimed to develop, apply, and validate an infrared spectrophotometry method used for qualitative and quantitative analyses of tranexamic acid in marketed tablets. (2) Methods: This was a descriptive observational study that consisted of several stages: determining the specific wavenumber for analysis, obtaining a simple linear regression equation, analyzing tranexamic acid both qualitatively and quantitatively, and validating the developed method for routine analysis. (3) Results: The peak analysis obtained a range of baseline wavenumbers from 1679.17 to $1295.25 \mathrm{~cm}^{-1}$. The regression equation obtained was $Y=310.8527 \times X+0.9718$, and the coefficient of determination $\left(\mathrm{R}^{2}\right)$ obtained was 0.9994 . The tranexamic acids in marketed tablets overall have a similarity index value of more than 0.90 and overall have levels ranging between $97.0 \%$ and $103.0 \%$. The infrared spectrophotometry method that was successfully developed, applied, and validated for qualitative and quantitative analyses of tranexamic acid in marketed tablets meets the requirements both qualitatively and quantitatively of the tablet monograph. (4) Conclusions: The infrared spectrophotometry method has been validated and meets the requirements for accuracy, precision, detection limit, quantitation limit, linearity, range, and specificity.

Keywords: validation; infrared spectrophotometry; qualitative; quantitative; tranexamic acid

\section{Introduction}

Hemostasis is the body's natural process of stopping bleeding either spontaneously or not spontaneously [1]. Bleeding in the body stimulates the body's natural mechanisms to clot the blood to stop bleeding [2]. This condition is the cause of pathological conditions and requires therapy, which is tranexamic acid [3]. Tranexamic acid is a lysine-derived synthetic antifibrinolytic that acts by reversibly blocking the lysine-binding region on the plasminogen molecule [4]. This medicine should be used according to a doctor's prescription and in the short term. It prevents side effects and organ damage, such as kidney and bone marrow damage [5,6]. Tranexamic acid is marketed in a tablet dosage form available in strengths of $500 \mathrm{mg}$ per tablet [7]. Drugs marketed must meet aspects of efficacy, quality, and safety [8]. The finished medicinal product must meet the quality requirements stated in the monograph before being marketed [9]. 
Several previous studies for qualitative and quantitative analyses of tranexamic acid have been conducted. An analysis using ultraviolet spectrophotometry was carried out with various specific reaction treatments [10], and an analysis using infrared spectrophotometry was carried out using first order derivatization treatment [11]. Meanwhile, highperformance liquid chromatography analysis with various detectors can be applied to analyze tranexamic acid with or without treatment [12-15]. Several previous reports about tranexamic acid analyses are shown in Table 1.

Table 1. Reported previous analyses of tranexamic acid.

\begin{tabular}{|c|c|c|}
\hline Method & Detector & Treatment \\
\hline Spectrophotometry & $\begin{array}{l}\text { Ultraviolet Visible [10] } \\
\text { Infrared [11] }\end{array}$ & $\begin{array}{c}\text { 2,6-Dichloroquinone-4-Chlorimide [10] } \\
\text { First Order [11] }\end{array}$ \\
\hline $\begin{array}{l}\text { High-Performance Liquid } \\
\text { Chromatography }\end{array}$ & $\begin{array}{c}\text { Mass Spectrophotometry [13] } \\
\text { Evaporative Light Scattering [14] } \\
\text { Ultraviolet-Visible Detector [12] } \\
\text { Photo Diode Array [15] }\end{array}$ & $\begin{array}{c}{[13]} \\
{[14]} \\
\text { Benzene Sulfonyl Chloride [12] } \\
{[15]}\end{array}$ \\
\hline
\end{tabular}

The analytical research on tranexamic acid is limited because it lacks adequate chromophore and auxochrome groups. It is not easy to analyze using ultraviolet-visible spectrophotometry [16]. High-performance liquid chromatography is a complex method, requires a high cost, and cannot be used to analyze all samples [17]. To overcome the drawbacks of high-performance liquid chromatography analysis, an alternate technique for qualitative and quantitative tranexamic acid analysis must be developed. Figure 1 presents the molecular structure of tranexamic acid. Given that tranexamic acid is the medicine of choice for bleeding, it necessitates a quick and valid examination to guarantee that it fits qualitative and quantitative preparation standards [18,19].

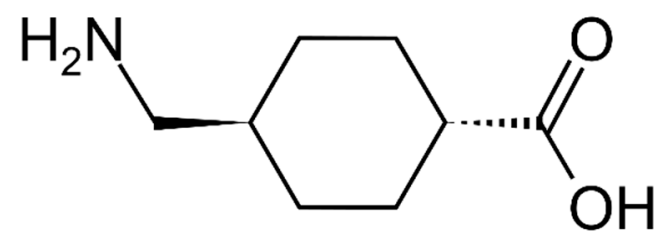

Figure 1. Molecular structure of tranexamic acid.

Infrared spectrophotometry measurements have the advantages of environmentfriendliness, simplicity of sample preparation, ease of operation, and short analysis time. Infrared spectrophotometry is widely used to analyze pharmaceutical products, environmental substances, and biological fluids [20]. Organic analysis can be performed, or potassium bromide pellets can be used. The researchers chose the potassium bromide pellet approach because it is less harmful to the environment than organic solvents. Previous research identified other active compounds using the potassium bromide pellet approach and the zero-order method. However, the use of tranexamic acid in tablet forms has never been investigated or verified [21].

Functional groups present in tranexamic acid are used for analysis by the infrared spectrophotometry method. Infrared spectrophotometry application in the pharmaceutical industry is very popular as a tool for qualitative analysis (identification) and quantitative analysis (determination) because of its good sensitivity [22]. Researchers are therefore encouraged to use the potassium bromide pellet and zero-order procedures to quantify tranexamic acid levels and confirm the analytical method considering this background.

The laboratory requires method validation because it can determine the level of confidence resulting from an analytical method. The validation findings of the analytical technique can be used as a reference to establish the method's validity so that it can be utilized in the routine analysis [23]. Revalidation should be done, even though the previous 
validation produced data following the acceptance criteria. The differences of differences in the equipment, reagents, analysts, or time will affect the sensitivity [24].

Based on the information presented above, the researchers were interested in establishing a direct analysis of the infrared spectrophotometry technique (zero-order without derivatives) as an alternative approach for evaluating tranexamic acid levels that was fast, straightforward, simple, and green. The method developed was then applied to determine the levels of tranexamic acid in marketed tablets. Validation of the analytical methods was also carried out to prove the validity of the analytical method before it is recommended for application in the pharmaceutical industry or government institutions as a quality-control method.

\section{Results}

\subsection{Preliminary Study of Infrared Spectrophotometry}

Figure 2 illustrates the overlay spectrum of potassium bromide (blue line) and tranexamic acid with a potassium bromide mixture (red line). The tranexamic acid spectrum was analyzed to obtain the specific wavenumbers and functional groups of tranexamic acid. Table 2 presents the specific wavenumbers and functional groups of tranexamic acid. Figure 3 illustrates the baseline and area for quantitative analysis of tranexamic acid.

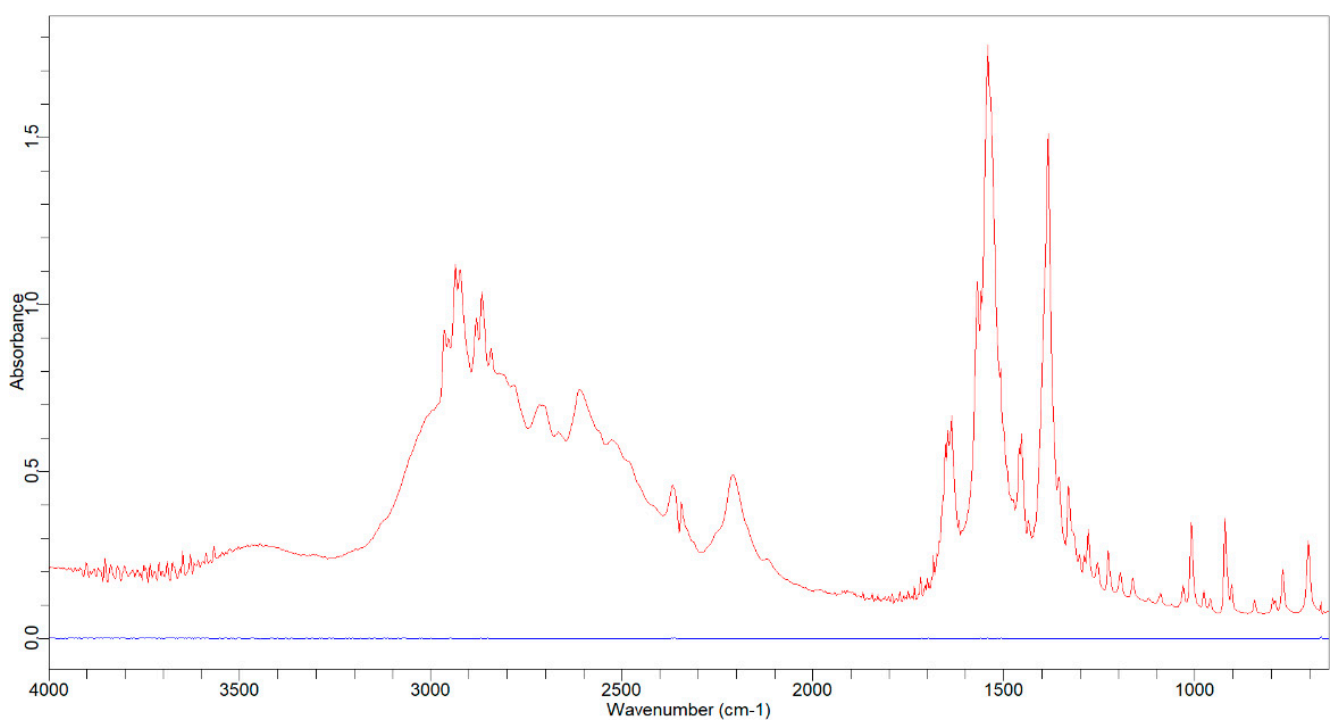

Figure 2. Overlay spectrum of potassium bromide (blue line) and tranexamic acid (red line).

Table 2. Specific wavenumbers and functional groups of tranexamic acid.

\begin{tabular}{|c|c|c|}
\hline Obtained Wavenumber & Reference Wavenumber & Functional Group/Fingerprint \\
\hline $2965.11 \mathrm{~cm}^{-1}$ & $\pm 3000 \mathrm{~cm}^{-1}$ (Strong \& Board) & -COOH (O-H Stretching) \\
\hline $769.73 \mathrm{~cm}^{-1}$ & $600 \mathrm{~cm}^{-1}$ to $800 \mathrm{~cm}^{-1}$ (Medium) & -COOH (O-H Bending) \\
\hline $1162.86 \mathrm{~cm}^{-1}$ and $1196.50 \mathrm{~cm}^{-1}$ & $1000 \mathrm{~cm}^{-1}$ to $1200 \mathrm{~cm}^{-1}$ (Medium) & - $\mathrm{COOH}(\mathrm{O}-\mathrm{H}$ Bending) \\
\hline $1569.18 \mathrm{~cm}^{-1}$ and $1541.34 \mathrm{~cm}^{-1}$ & $1300 \mathrm{~cm}^{-1}$ to $1600 \mathrm{~cm}^{-1}$ (Medium) & - $\mathrm{COOH}(\mathrm{O}-\mathrm{H}$ Bending) \\
\hline $1638.25 \mathrm{~cm}^{-1}$ & $<1700 \mathrm{~cm}^{-1}$ (Medium) & $-\mathrm{COOH}(\mathrm{C}=\mathrm{O}$ Stretching $)$ \\
\hline $1010.16 \mathrm{~cm}^{-1}$ and $922.53 \mathrm{~cm}^{-1}$ & $\pm 1050 \mathrm{~cm}^{-1}$ (Medium) & -COOH (C-O Stretching) \\
\hline $3445.97 \mathrm{~cm}^{-1}$ & $3650-3250 \mathrm{~cm}^{-1}$ (Medium) & $-\mathrm{NH}_{2}$ (N-H Stretching) \\
\hline $1638.22 \mathrm{~cm}^{-1}$ & $1650-1590 \mathrm{~cm}^{-1}$ (Medium) & $-\mathrm{NH}_{2}(\mathrm{~N}-\mathrm{H}$ Bending) \\
\hline $1030.64 \mathrm{~cm}^{-1}$ & $1090-1020 \mathrm{~cm}^{-1}$ (Medium) & $-\mathrm{NH}_{2}$ (C-N Stretching) \\
\hline $2715.39 \mathrm{~cm}^{-1}$ and $2611.01 \mathrm{~cm}^{-1}$ & $>3000 \mathrm{~cm}^{-1}$ (Medium) & Alkane (C-H Stretching) \\
\hline $2935.05 \mathrm{~cm}^{-1}$ & $\pm 2935 \mathrm{~cm}^{-1}$ (Medium) & Alkane (C-H Stretching) \\
\hline $2879.43 \mathrm{~cm}^{-1}$ and $2868.32 \mathrm{~cm}^{-1}$ & $\pm 2860 \mathrm{~cm}^{-1}$ (Medium) & Alkane (C-H Stretching) \\
\hline $2210.28 \mathrm{~cm}^{-1}$ & $\pm 2200 \mathrm{~cm}^{-1}$ (Medium) & Alkyne ( $\mathrm{C} \equiv \mathrm{C}$ Stretching) \\
\hline $1453.69 \mathrm{~cm}^{-1}$ and $1384.70 \mathrm{~cm}^{-1}$ & $\pm 1470 \mathrm{~cm}^{-1}$ (Medium) & Alkane (C-H Bending) \\
\hline $702.57 \mathrm{~cm}^{-1}$ & $\pm 720 \mathrm{~cm}^{-1}$ (Medium) & Alkane (C-H Bending) \\
\hline
\end{tabular}




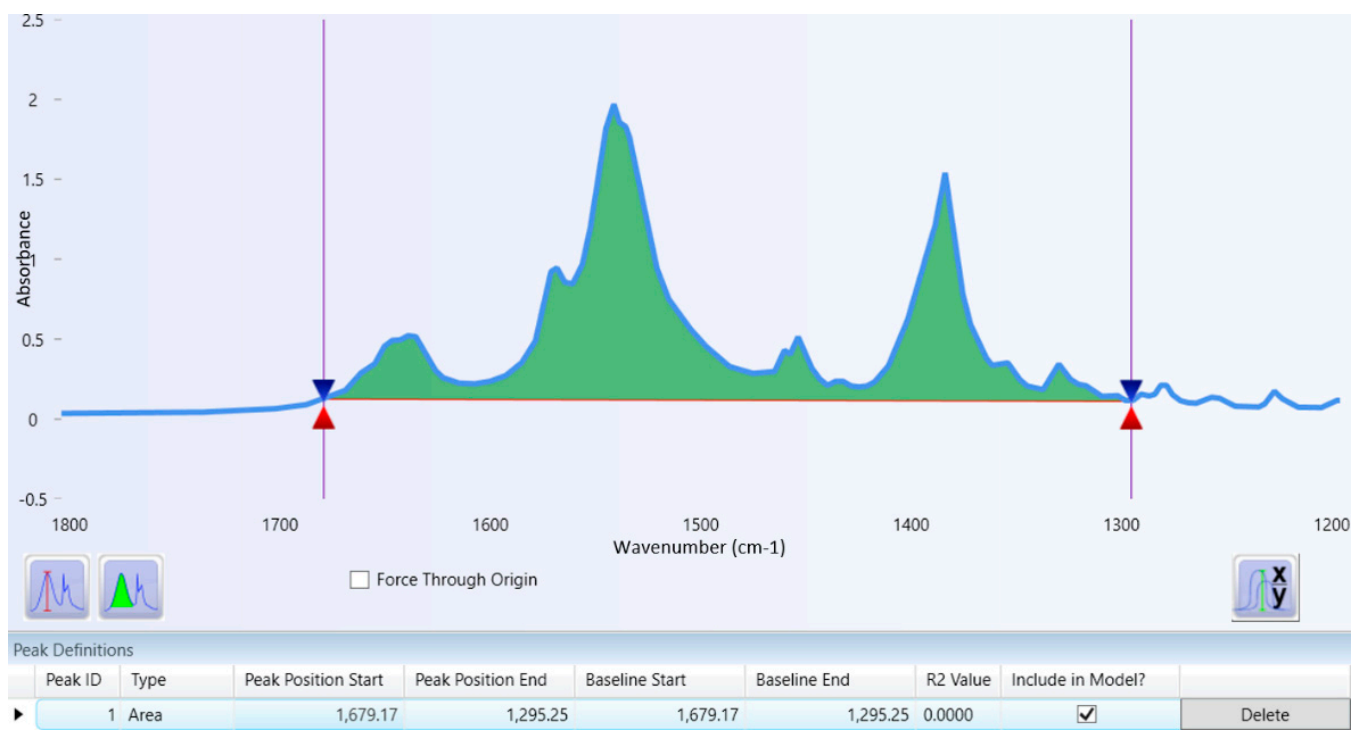

Figure 3. Baseline and area for quantitative analysis of tranexamic acid.

The infrared spectrum, as shown in Figure 2, from potassium bromide (blue line) does not provide any absorption in the measurements (after background measurements with potassium bromide)—-the specific wavenumbers are in Table 2 .

\subsection{Regression of Tranexamic Acid}

A set of tranexamic acid concentrations was measured and analyzed to obtain a series of tranexamic acid areas. Figure 4 illustrates the overlay spectrum of tranexamic acid regression data set series. The concentration and area series from the tranexamic acid regression data set and the tranexamic acid calibration curve are shown in Table 3 and Figure 5, respectively. The regression equation and coefficient of determination were constructed using the series concentration and area from the tranexamic acid regression data set acquired from the analysis findings in Table 3 . The regression equation obtained was $y=310.8527 x+0.9718$, and the coefficient of determination $\left(R^{2}\right)$ obtained was 0.9994 , as illustrated in Figure 5.

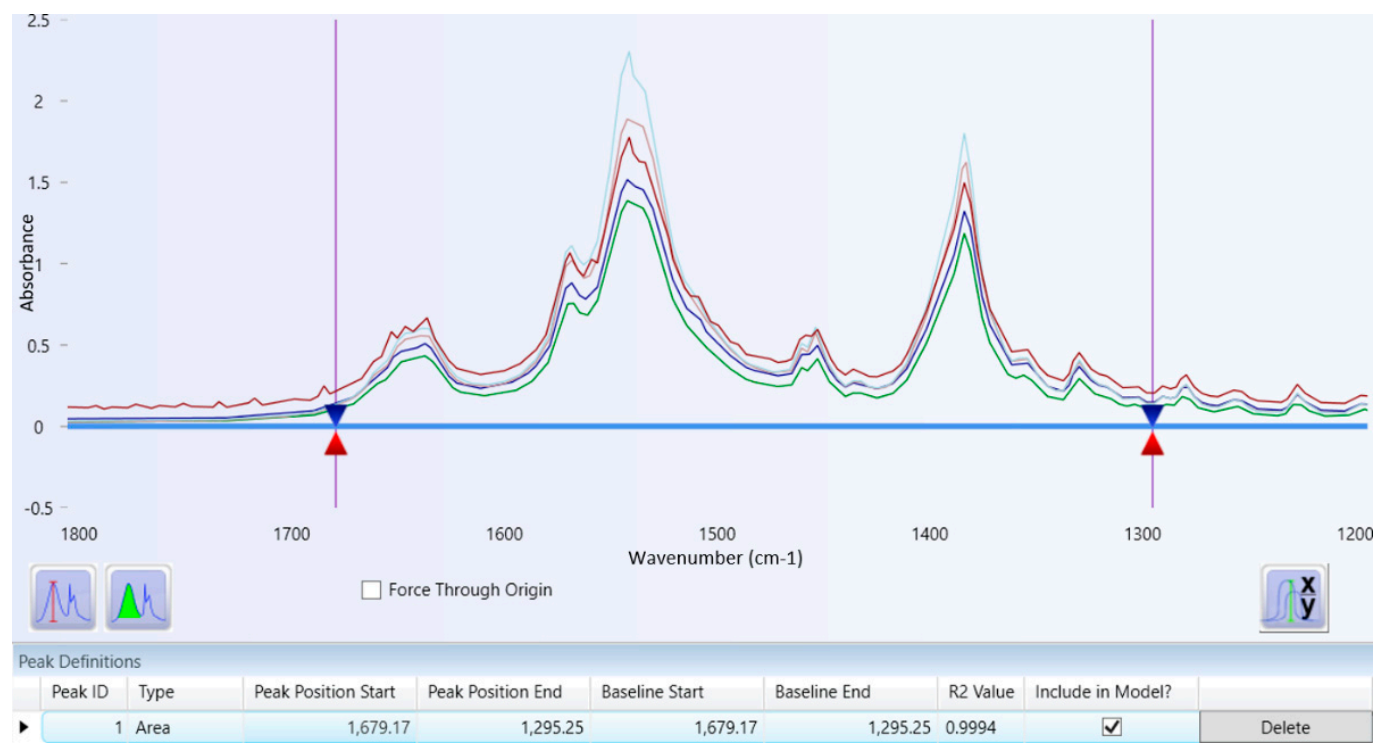

Figure 4. Overlay spectrum of regression data set series of tranexamic acid. 
Table 3. Series concentration and series area from the regression data set series of tranexamic acid.

\begin{tabular}{ccc}
\hline Number & Concentration (\%) & Area (AU) \\
\hline 1 & 0.00 & 0.2444308000 \\
2 & 0.40 & 125.8313214400 \\
3 & 0.45 & 142.4944207150 \\
4 & 0.50 & 158.3252190500 \\
5 & 0.55 & 169.8243798000 \\
6 & 0.60 & 186.2427745000 \\
\hline
\end{tabular}

\section{Calibration Curve of Tranexamic Acid (Concentration versus Area)}

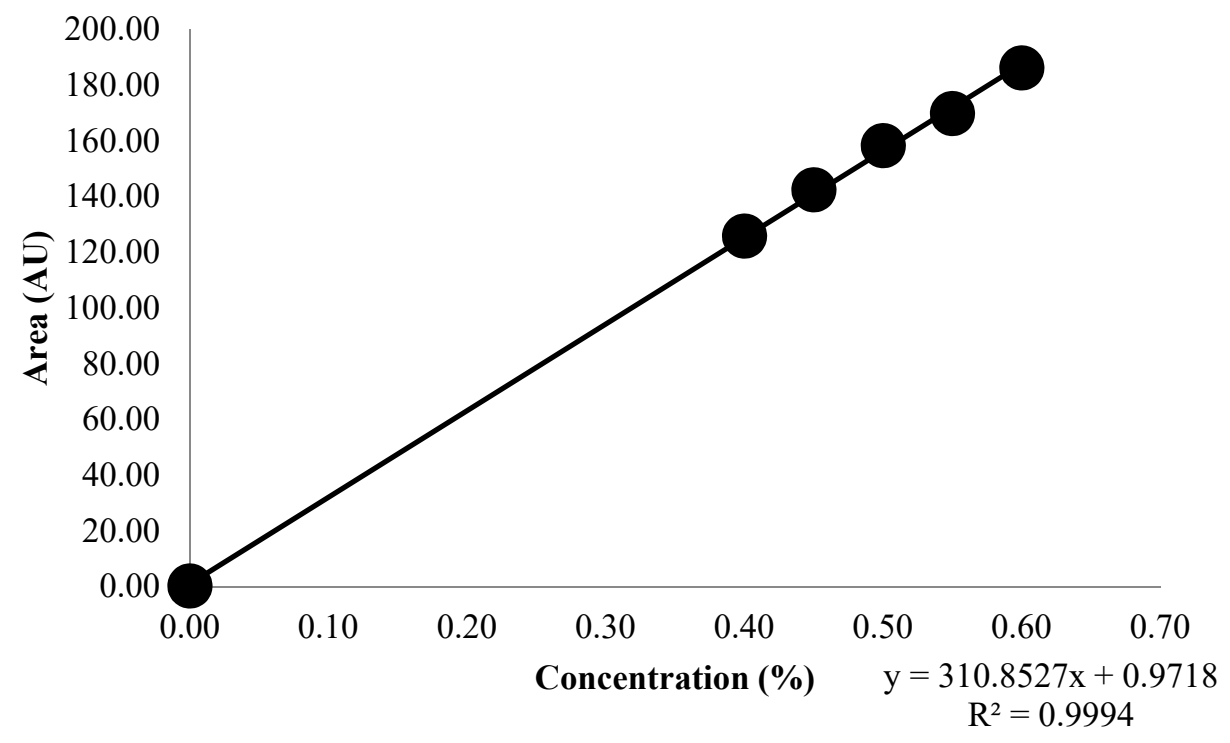

Figure 5. Calibration curve of tranexamic acid.

\subsection{Analysis of Tranexamic Acid in Marketed Tablets}

Table 4 presents the results for qualitative and quantitative analyses of tranexamic acid in marketed tablets.

Table 4. Results for qualitative analysis and quantitative analysis of tranexamic acid in marketed tablets.

\begin{tabular}{|c|c|c|c|}
\hline Number & Sample & $\begin{array}{l}\text { Qualitative Analysis } \\
\text { (Tranexamic Acid } \\
\text { Similarity Index) }\end{array}$ & $\begin{array}{l}\text { Quantitative Analysis } \\
\text { (Tranexamic Acid Level) }\end{array}$ \\
\hline 1 & $\begin{array}{c}\text { Transamin }{ }^{\circledR} 500 \mathrm{mg} \text { Tablet } \\
\text { (Otto Pharmaceutical } \\
\text { Industries) }\end{array}$ & 0.9083 & $97.56 \% \pm 0.19 \%$ \\
\hline 2 & $\begin{array}{c}\text { Plasminex }{ }^{\circledR} 500 \mathrm{mg} \text { Tablet } \\
\text { (Sanbe Farma) }\end{array}$ & 0.9157 & $101.80 \% \pm 0.24 \%$ \\
\hline 3 & $\begin{array}{c}\text { Pytramic }{ }^{\circledR} 500 \text { mg Tablet } \\
\text { (Pyridam Farma) }\end{array}$ & 0.9065 & $99.73 \% \pm 0.22 \%$ \\
\hline 4 & $\begin{array}{c}\text { Kalnex }{ }^{\circledR} 500 \text { mg Tablet } \\
\text { (Kalbe Farma) }\end{array}$ & 0.9279 & $102.74 \% \pm 0.27 \%$ \\
\hline 5 & $\begin{array}{c}\text { Nexa }{ }^{\circledR} 500 \text { mg Tablet } \\
\text { (Sanbe Farma) }\end{array}$ & 0.9189 & $100.47 \% \pm 0.22 \%$ \\
\hline 6 & $\begin{array}{c}\text { Nexitra }^{\circledR} 500 \mathrm{mg} \text { Tablet } \\
\text { (Ifars) }\end{array}$ & 0.9192 & $99.50 \% \pm 0.21 \%$ \\
\hline 7 & $\begin{array}{l}\text { Tranexamic Acid } 500 \mathrm{mg} \text { Tablet } \\
\text { (First Medifarma) }\end{array}$ & 0.9027 & $98.65 \% \pm 0.21 \%$ \\
\hline 8 & $\begin{array}{c}\text { Tranexamic Acid } 500 \mathrm{mg} \text { Tablet } \\
\text { (Bernofarm) }\end{array}$ & 0.9122 & $102.55 \% \pm 0.26 \%$ \\
\hline
\end{tabular}




\section{Discussion}

\subsection{Preliminary Study of Infrared Spectrophotometry}

This investigation started with background measurements using potassium bromide pellets and then the combination of potassium bromide pellets and tranexamic acid in a pellet form was observed to see how potassium bromide affected tranexamic acid analysis. These results prove that potassium bromide does not interfere with the tranexamic acid analysis. The infrared spectrum of tranexamic acid (red line) in Figure 2 provides an absorption response similar to that in the literature, both in terms of spectrum and specific wave numbers [25]. Tranexamic acid was quantified using three primary peaks in the fingerprint area with wavenumbers ranging from 1800 to $650 \mathrm{~cm}^{-1}$, notably wave numbers $1638.2,1541.3$, and $1384.7 \mathrm{~cm}^{-1}$ [26-28].

The addition of tranexamic acid standard spectrum performed a qualitative analysis of tranexamic acid into the system library. Infrared spectrophotometry provides a computerized facility for qualitative analysis by matching unknown sample spectrums against spectrum data contained in the system library. This action resulted in the similarity between the sample spectrum that is qualitatively unknown and the standard spectrum in the system library [29]. The particular wavenumbers in Table 2 obtained from the tranexamic acid analysis illustrate the proximity to the wavenumbers in the literature and the related functional groups present in the molecular structure of tranexamic acid. [30].

The fingerprint capability of infrared spectrophotometry offers the convenience of analyzing the unique chemical characteristics of each compound in the sample. The procedures used in this research have been able to ensure the homogeneity and consistency of the results. Before pressing, the tranexamic acid and potassium bromide combination was weighed in equal parts $(40 \mathrm{mg})$. Furthermore, pressing was done with the same tonnage (2.0 tons) and at the same time ( $2 \mathrm{~min})$. It is feasible to achieve a homogenous film thickness with homogeneity in the weight of the tested mixture, pressing tonnage, and pressing duration [31].

A quantitative analysis was carried out on peak area analysis by calculating the sum area of the three main peaks. The technique for obtaining the peak area is typical under the band area, and it begins with identifying the baseline and concludes with determining the area. The peak baseline analysis obtained a range of baseline wavenumbers from 1679.17 to $1295.25 \mathrm{~cm}^{-1}$. In that wavenumber, the peak area of the three main peaks will be completely covered, as shown in Figure 3. The peak baseline is the lowest point on both sides of the peak spectrum to be analyzed. The peak area is the area covered by the peak and baseline spectrum. Quantitative analysis using the peak area provides better accuracy and precision and avoids an analysis error using peak absorbance or peak height [32].

\subsection{Regression of Tranexamic Acid}

Quantitative analysis using infrared spectrophotometry utilizes regression data sets that will produce a regression equation. A greater tranexamic acid content in the pellets resulted in a larger tranexamic acid area, as shown in Figure 4. In accordance with the Lambert-Beer law, which follows in the quantitative analysis by infrared spectrophotometry, it can be assumed that there is a linear relationship between the concentration of the compound and the response (absorbance or height or area) produced by the compound [33].

The regression equation obtained can analyze the concentration of tranexamic acid in a tablet with an unknown concentration. Good regression data sets have a coefficient of determination that is more than 0.99 , indicating that the concentration can be determined from the area using the regression equation [34].

\subsection{Analysis of Tranexamic Acid in Marketed Tablets}

Analysis of tranexamic acid in marketed tablets was performed using the developed infrared spectrophotometric method. Measurements were made of the area with a predetermined baseline. Qualitative analysis with the tranexamic acid similarity index parameter and quantitative analysis with the tranexamic acid level parameter were carried out. 
The findings of the qualitative analysis of tranexamic acid in marketed tablets in Table 4 show that all of the tablets examined on the market contain tranexamic acid, as evidenced by an overall similarity index value of more than 0.90 . The similarity index is a value that indicates the similarity between the unknown sample and the known standard in the system library; the closer to 1.00 the similarity index is, the more similar the samples and standards [35]. A good similarity index value is not less than 0.80, indicating the similarity between unknown samples and standards in the system library [36].

The quantitative analysis of tranexamic acid in marketed tablets findings in Table 4 shows that all tablets on the market satisfied the standards of the tranexamic acid tablet monograph, as evidenced by overall values ranging from 97.0 to $103.0 \%$. Pharmaceutical preparation distributed in the market is declared good quality if it meets the monograph requirements listed in the compendial both qualitatively and quantitatively [37]. The Indonesian Pharmacopoeia includes tranexamic acid tablet monographs that require tranexamic acid levels in tablets to be no less than $95.0 \%$ and no more than 105.0 percent of the quantity specified on the label [38].

\subsection{Validation of the Infrared Spectrophotometry Method}

The validation of the developed analysis method by infrared spectrophotometry for qualitative analysis and quantitative analysis of tranexamic acid aims to prove and ensure that the validity of the analysis method has been suitable for its purpose [39]. To obtain valid data, an analyst must pay attention to the processes and procedures carried out during the analysis and validate the analytical methods before applying them to routine analysis. The validation of the analytical method is the final stage that determines the quality of the data generated from an analytical method [40].

The analytical method was validated with parameters of accuracy, precision, detection limit, quantitation limit, linearity, and range. Validation of accuracy parameters using a recovery percentage resulted in a value of $99.88 \%$. These results meet the requirements of the accuracy test with the requirements of acceptance for a recovery percentage between $99 \%$ and $101 \%$, indicating that the method developed has good accuracy [41]. The validation of precision parameters using the relative standard deviation resulted in a value of $0.50 \%$. These results meet the requirements of the precision test with the requirements of acceptance for a relative standard deviation less than $2 \%$, indicating that the method developed has good precision [42].

The validation of detection limit parameters and quantitation limit parameters using the series concentration and the series area from the regression data set resulted in respective values of $0.0079 \%$ and $0.0239 \%$. These values are much lower than the target analysis concentration of $0.50 \%$ (the detection limit concentration obtained is 63 times lower, and the quantitation limit concentration obtained is 21 times lower than the concentration). The lower the detection and quantitation limit concentration, the better the method developed [43] and the higher the sensitivity [44].

The validation of linearity parameters using the coefficient of correlation (R) resulted in a value of 0.9997 . These results meet the requirements of the linearity test with the requirements of acceptance for the correlation coefficient of more than 0.99 , indicating that the method developed has good linearity (good relationship between concentration abscissa, $X$, and area ordinate, $Y$ ) [45]. The validation of the range parameter gives a concentration range of $0.40 \%$ to $0.60 \%$. The range of an analytical method is the interval between the lower limit and the upper limit of the analyte concentration in an analytical approach that meets the appropriate requirements for accuracy, precision, and linearity [46].

The qualitative analysis indicates the similarity of the infrared spectrum of the tranexamic acid in marketed tablets with the infrared spectrum of the standard tranexamic acid. The quantitative analysis indicates that the concentration of tranexamic acid in marketed tablets depends on the area of the tranexamic acid standard. The regression model indicates the level of determination and the level of a good relationship between concentration and area. The infrared spectrophotometric method that was successfully developed is 
specifically for the qualitative analysis and quantitative analysis of tranexamic acid in marketed tablet preparation. Reasonable specificity is shown from regression, qualitative analysis, and quantitative analysis [47].

\section{Materials and Methods}

\subsection{Tools and Materials}

This research used the following tools and materials: Fourier transform infrared spectrophotometer with zinc selenium as a beam splitter and a transmission module for a potassium bromide pellet holder (Agilent-Cary 630, Yishun, Singapore), personal computer (Lenovo, Beijing, China), printer (Canon, Tokyo, Japan), analytical balance (Precisa-LX 320, Dietikon, Switzerland), pellet press (Specac-Hanheld, Orpington, United Kingdom), porcelain mortar and pestle (Merck, Jakarta, Indonesia), agate mortar and pestle (Merck, Jakarta, Indonesia), glassware (Iwaki, Jakarta, Indonesia), Microlab (Agilent-OQ, PC, Quant, Lite, Yishun, Singapore), statistical package for the social sciences (International Business Machines Corporation, Selangor, Malaysia), tranexamic acid (Merck, Jakarta, Indonesia), potassium bromide (Merck, Jakarta, Indonesia), Transamin ${ }^{\circledR} 500 \mathrm{mg}$ tablet (Otto Pharmaceutical Industries, Bandung, Indonesia), Plasminex ${ }^{\circledR} 500$ mg tablet (Sanbe Farma, Bandung, Indonesia), Pytramic ${ }^{\circledR} 500 \mathrm{mg}$ tablet (Pyridam Farma, Cianjur, Indonesia), Kalnex ${ }^{\circledR} 500$ mg tablet (Kalbe Farma, Jakarta, Indonesia), Nexa ${ }^{\circledR} 500$ mg tablet (Sanbe Farma, Bandung, Indonesia), Nexitra ${ }^{\circledR} 500 \mathrm{mg}$ tablet (Ifars, Solo, Indonesia), tranexamic acid $500 \mathrm{mg}$ tablet (First Medifarma, Sidoarjo, Indonesia), and tranexamic acid $500 \mathrm{mg}$ tablet (Bernofarm, Sidoarjo, Indonesia).

\subsection{Preliminary Study of Infrared Spectrophotometry}

The preliminary study of tranexamic acid uses the Kotadiya and Khristi [48] method with minor modifications in the weight and concentration. Tranexamic acid standard and a potassium bromide mixture was prepared to obtain the final concentration of $0.5 \%$ tranexamic acid in potassium bromide with a gradual dilution using the following procedure: weighing $13.0 \mathrm{mg}$ of tranexamic acid, weighing $987.0 \mathrm{mg}$ of potassium bromide, mixing into the agate mortar, grinding the mixture with agate pestle until it was homogeneous (obtained initial mixture with a concentration of tranexamic acid of $1.3 \%$ in potassium bromide); weighing $38.5 \mathrm{mg}$ of the initial mix; weighing $61.5 \mathrm{mg}$ of potassium bromide; mixing into the agate mortar; grinding with agate pestle until mixed homogeneously (obtained final mixture with a concentration of $0.5 \%$ of tranexamic acid in potassium bromide); weighing the final mixture in the amount of $40.0 \mathrm{mg}$ put into the pellet press; pressing at a pressure of 2.0 tons for $2.0 \mathrm{~min}$; measuring the spectrum using an infrared spectrophotometry equipped with a transmission module, connected to the personal computer and printer, with the Microlab application installed; analyzing the pellet at wave numbers 4000 to $650 \mathrm{~cm}^{-1}$; measuring the background with the potassium bromide pellet; analyzing the potassium bromide pellet and mixture of tranexamic acid with a potassium bromide pellet to obtain the specific wavenumbers of tranexamic acid for qualitative and quantitative analyses.

\subsection{Regression of the Tranexamic Acid Standard}

The simple linear regression of tranexamic acid uses the Singh et al. [49] method with minor modifications in the weight and concentration. A tranexamic acid standard and potassium bromide mixture regression data set was prepared to obtain the final concentration from $0.00 \%$ to $0.50 \%$ tranexamic acid in potassium bromide with a gradual dilution using the following procedure: weighing $13.0 \mathrm{mg}$ of tranexamic acid, weighing $987.0 \mathrm{mg}$ of potassium bromide, mixing into the agate mortar, and grinding with agate pestle until homogeneous (obtained initial mixture with a concentration of tranexamic acid of $1.3 \%$ in potassium bromide); weighing the initial mixture of $30.8,34.7,38.5,42.4$, and $46.2 \mathrm{mg}$; weighing the potassium bromide of $69.2,65.3,61.5,57.6$, and $53.8 \mathrm{mg}$, mixing into the agate mortar, grinding with agate pestle until mixed homogeneously (obtained final 
mixture with a concentration of $0.40 \%, 0.45 \%, 0.50 \%, 0.55 \%$, and $0.60 \%$ of tranexamic acid in potassium bromide); weighing the final mixture in the amount of $40.0 \mathrm{mg}$ put into the pellet press; pressing at a pressure of 2.0 tons for $2.0 \mathrm{~min}$; measuring the spectrum using an infrared spectrophotometer equipped with a transmission module, connected to the personal computer and printer, and with a Microlab application installed and a statistical package for the social sciences application; analyzing the pellet at wave numbers 4000 to $650 \mathrm{~cm}^{-1}$; measuring the background with the potassium bromide pellet; analyzing the potassium bromide pellet and the regression data set mixture of tranexamic acid with a potassium bromide pellet to obtain the regression equation and coefficient of determination.

\subsection{Analysis of Tranexamic Acid in Marketed Tablets}

The analysis of tranexamic acid in marketed tablets uses the method from Sheeja and Swapna [50] with minor modifications in the weight and concentration. The mixture of tranexamic acid in marketed tablets and potassium bromide was prepared to obtain the final concentration of $0.5 \%$ tranexamic acid in potassium bromide with a gradual dilution using the following procedure: weighing 20 tablets, inserting them in a porcelain mortar, and grinding them using a porcelain pestle until they became a homogeneous powder; weighing an amount of the powder equivalent to $13.0 \mathrm{mg}$ of tranexamic acid; weighing $987.0 \mathrm{mg}$ of potassium bromide, mixing into the agate mortar, and grinding it with the agate pestle until it was homogeneous (obtained initial mixture with concentration of tranexamic acid of $1.3 \%$ in potassium bromide); weighing $38.5 \mathrm{mg}$ of the initial mix, weighing $61.5 \mathrm{mg}$ of potassium bromide, mixing all ingredients into the agate mortar, and grinding with an agate pestle until mixed homogeneously (obtaining the final mixture with a concentration of tranexamic acid of $0.5 \%$ in potassium bromide); weighing the final mixture in the amount of $40.0 \mathrm{mg}$ put into the pellet press; pressing at a pressure of 2.0 tons for $2.0 \mathrm{~min}$; measuring the spectrum by using an infrared spectrophotometer equipped with a transmission module, connected to the personal computer and printer, with a Microlab application installed; analyzing the pellet at wave numbers 4000 to $650 \mathrm{~cm}^{-1}$; measuring the background with the potassium bromide pellet; analyzing qualitatively samples of tranexamic acid tablets with the similarity index (similarity of sample spectrum to standard spectrum); analyzing quantitatively samples of tranexamic acid tablets by calculating the level of tranexamic acid in the sample with a predetermined concentration of tranexamic acid using a regression equation.

\subsection{Validation of the Infrared Spectrophotometry Method}

The validation of the analysis method was based on the method from Judeh et al. [51] and Naz et al. [52], with minor modifications in weight and concentration. Validation includes accuracy, precision, detection limit, quantitation limit, linearity, and range. The accuracy of the analysis method with the recovery percentage parameter was carried out using a standard addition method for three specific concentrations (80\%, 100\%, and 120\%). Each specific concentration contained a 30\% standard added to a $70 \%$ analyte for three replications, then was analyzed using the same technique as in a sample analysis. The precision of the analysis method with the relative standard deviation parameter against the data obtained from three specific concentrations and three replications for each specific concentration. The linearity of the analysis method with the coefficient of the correlation parameter was determined using data obtained from the regression data set. The detection limit and the quantitation limit of the analysis method were determined using the data obtained from the regression data set based on the standard deviation of the response and the slope. The range of the analysis method is determined from the upper and lower limits of concentration that meet the criteria of accuracy, precision, and linearity [53]. The specificity of the analysis method was determined from the regression data set and qualitative and quantitative analyses of the sample [54]. 


\section{Conclusions}

The infrared spectrophotometry method has been successfully developed for the analysis of tranexamic acid. It has been applied for qualitative analysis and quantitative analysis of tranexamic acid in marketed tablets to ensure that all marketed tablets meet the qualitative and quantitative requirements of the tablet monograph stated in the Indonesian Pharmacopoeia, 6th Edition, 2020. The infrared spectrophotometry method has been verified and shown to be accurate, precise, detectable, quantifiable, linear, range, and specific.

Author Contributions: Conceptualization, N.N. and L.M.; methodology, N.N.; software, L.M.; validation, N.N., L.M. and B.M.S.; formal analysis, N.N. and L.M.; investigation, N.N., B.M.S. and S.G.; resources, B.M.S.; data curation, E.D.L.P. and T.K.B.; writing-original draft preparation, N.N.; writing-review and editing, L.M. and B.M.S.; visualization, E.D.L.P.; supervision, N.N.; project administration, N.N.; funding acquisition, L.M. All authors have read and agreed to the published version of the manuscript.

Funding: This research support from Institut Kesehatan Deli Husada Deli Tua and Mutiara Mukti Farma.

Institutional Review Board Statement: Not applicable.

Informed Consent Statement: Not applicable.

Data Availability Statement: The data presented in this study are available in this article.

Acknowledgments: The authors would like to thank Institut Kesehatan Deli Husada Deli Tua for the research funds and Mutiara Mukti Farma for availing the research facilities.

Conflicts of Interest: The authors declare no conflict of interest.

Sample Availability: Samples are available from the authors.

\section{References}

1. Marinho, D.S. Perioperative hyperfibrinolysis-Physiology and pathophysiology. Braz. J. Anesthesiol. 2021, 71, 65-75. [CrossRef] [PubMed]

2. Lichota, A.; Szewczyk, E.M.; Gwozdzinski, K. Factors affecting the formation and treatment of thrombosis by natural and synthetic compounds. Int. J. Mol. Sci. 2020, 21, 7975. [CrossRef] [PubMed]

3. Gale, A.J. Continuing education course \#2: Current understanding of hemostasis. Toxicol. Pathol. 2011, 39, 273-280. [CrossRef]

4. Scarafoni, E.E. A systematic review of tranexamic acid in plastic surgery: What's new? Plast. Reconstr. Surg.-Glob. Open 2021, 9, 3172. [CrossRef]

5. Joseph, J.; Martinez-Devesa, P.; Bellorini, J.; Burton, M.J. Tranexamic acid for patients with nasal haemorrhage (epistaxis). Cochrane Database Syst. Rev. 2018, 12, CD004328. [CrossRef] [PubMed]

6. Pabinger, I.; Fries, D.; Schöchl, H.; Streif, W.; Toller, W. Tranexamic acid for treatment and prophylaxis of bleeding and hyperfibrinolysis. Wien. Klin. Wochenschr. 2017, 129, 303-316. [CrossRef] [PubMed]

7. Soundarya, S.; Srinivasan, M.S. Tranexamic acid in dermatology. Ann. Trop. Med. Public Health 2020, 23, 231-509. [CrossRef]

8. Menditto, E.; Orlando, V.; de Rosa, G.; Minghetti, P.; Musazzi, U.; Cahir, C.; Kurczewska-Michalak, M.; Kardas, P.; Costa, E.; Lobo, J.S.; et al. Patient centric pharmaceutical drug product design-The impact on medication adherence. Pharmaceutics 2020, 12, 44. [CrossRef] [PubMed]

9. Prakash, G.; Chandra, S.A.; Sandhya, P.; Bidur, C.; Samir, D. Pharmacopoeial comparison of in-process and finished product quality control test for pharmaceutical tablets. GSC Biol. Pharm. Sci. 2020, 11, 155-165. [CrossRef]

10. Gadkariem, E.A.; Mohamed, M.A.; Jabbir, M.A. Spectrophotometry method for the determination of tranexamic acid in bulk and dosage forms. World Appl. Sci. J. 2012, 19, 1263-1267.

11. Nugrahani, I.; Aulia, W.N. The performance of derivate FTIR spectrophotometry method compared to colorimetry for tranexamic acid tablet content determination. Pharmaciana 2018, 8, 11-24. [CrossRef]

12. Ashfaq, M.; Aslam, A.; Mustafa, G.; Danish, M.; Nazar, M.F.; Asghar, M.N. Derivatization/chromophore introduction of tranexamic acid and its HPLC determination in pharmaceutical formulations. J. Assoc. Arab. Univ. Basic Sci. 2015, 17, 51-56. [CrossRef]

13. Delyle, S.G.; Abe, E.; Batisse, A.; Tremey, B.; Fischler, M.; Devillier, P.; Alvarez, J.C. A validated assay for the quantitative analysis of tranexamic acid in human serum by liquid chromatography coupled with electrospray ionisation mass spectrometry. Clin. Chim. Acta 2010, 411, 438-443. [CrossRef]

14. Patil, K.R.; Rane, V.P.; Sangshetti, J.N.; Shinde, D.B. Assay determination of tranexamic acid in pharmaceutical dosage form (tablet) using HPLC and ELS detector. Eurasian J. Anal. Chem. 2010, 5, 204-211. 
15. Patil, R.; Ahmed, A.K.L.; Firke, S.; Pawar, D. RP-HPLC PDA analysis of tranexamic acid in bulk and tablet dosage form. Anal. Chem. Lett. 2017, 7, 813-821. [CrossRef]

16. Sher, N.; Fatima, N.; Perveen, S.; Siddiqui, F.A.; Sial, A.W. Pregabalin and tranexamic acid evaluation by two simple and sensitive spectrophotometric methods. Int. J. Anal. Chem. 2015, 2015, 241412. [CrossRef] [PubMed]

17. Md Noh, M.F.; Gunasegavan, R.D.N.; Khalid, N.M.; Balasubramaniam, V.; Mustar, S.; Abd Rashed, A. Recent techniques in nutrient analysis for food composition database. Molecules 2020, 25, 4567. [CrossRef] [PubMed]

18. Ker, K.; Roberts, I.; Chaudhri, R.; Fawole, B.; Beaumont, D.; Balogun, E.; Prowse, D.; Pepple, T.; Javaid, K.; Kayani, A.; et al. WOMAN-2 trial collaborators. Tranexamic acid for the prevention of postpartum bleeding in women with anaemia: Study protocol for an international, randomised, double-blind, placebo-controlled trial. Trials 2018, 19, 712. [CrossRef] [PubMed]

19. Sentilhes, L.; Senat, M.V.; le Lous, M.; Winer, N.; Rozenberg, P.; Kayem, G.; Verspyck, E.; Fuchs, F.; Azria, E.; Gallot, D.; et al. Tranexamic Acid for the Prevention of Blood Loss after Cesarean Delivery. N. Engl. J. Med. 2021, 384, 1623-1634. [CrossRef]

20. Hu, C.; Zhang, Y.; Zhou, Y.; Liu, Z.; Meng, Q.; Feng, X. A review of pretreatment and analysis of macrolides in food (Update Since 2010). J. Chromatogr. A 2020, 1634, 461662. [CrossRef] [PubMed]

21. Chen, Y.; Zou, C.; Mastalerz, M.; Hu, S.; Gasaway, C.; Tao, X. Applications of micro-fourier transform infrared spectroscopy (FTIR) in the geological sciences-A review. Int. J. Mol. Sci. 2015, 16, 30223-30250. [CrossRef]

22. Nugrahani, I.; Musaddah, M. Development and validation analysis of acyclovir tablet content determination method using FTIR. Int. J. Appl. Pharm. 2016, 8, 43-47.

23. Güzel, B.; Canli, O. Method validation and measurement uncertainty of possible thirty volatile organic compounds (VOCs) presented in the polyethylene present in bottled drinking waters sold in Turkey. J. Anal. Sci. Technol. 2020, 11, 44. [CrossRef]

24. Saini, S.; Mandal, S.; Agarwal, D. Simultaneous estimation of admixture drugs by RP-HPLC: A Review. Asian J. Pharm. Res. Dev. 2020, 8, 180-185.

25. Shaikh, T.; Nafady, A.; Talpur, F.N.; Sirajuddin; Agheem, M.H.; Shah, M.R.; Sherazi, S.T.H.; Soomro, R.A.; Siddiqui, S. Tranexamic acid derived gold nanoparticles modified glassy carbon electrode as sensitive sensor for determination of nalbuphine. Sens. Actuators B Chem. 2015, 211, 359-369. [CrossRef]

26. Fahmi, Z.; Mudasir, M.; Rohman, A. Attenuated total reflectance-FTIR Spectra combined with multivariate calibration and discrimination analysis for analysis of patchouli oil adulteration. Indones. J. Chem. 2020, 20, 1-8. [CrossRef]

27. Nandiyanto, A.B.D.; Oktiani, R.; Ragadhita, R. How to read and interpret ftir spectroscope of organic material. Indones. J. Sci. Technol. 2019, 4, 97-118. [CrossRef]

28. Yan, Y.; Yang, Y.; Ran, M.; Zhou, X.; Zou, L.; Guo, M. Application of infrared spectroscopy in prediction of asphalt aging time history and fatigue life. Coatings 2020, 10, 959. [CrossRef]

29. Fanelli, S.; Zimmermann, A.; Totóli, E.G.; Salgado, H.R.N. FTIR spectrophotometry as a green tool for quantitative analysis of drugs: Practical application to amoxicillin. J. Chem. 2018, 2018, 3920810. [CrossRef]

30. Socaciu, C.; Fetea, F.; Ranga, F.; Bunea, A.; Dulf, F.; Socaci, S.; Pintea, A. Attenuated total reflectance-fourier transform infrared spectroscopy (ATR-FTIR) coupled with chemometrics, to control the botanical authenticity and quality of cold-pressed functional oils commercialised in Romania. Appl. Sci. 2020, 10, 8695. [CrossRef]

31. Hackshaw, K.V.; Miller, J.S.; Aykas, D.P.; Rodriguez-Saona, L. Vibrational spectroscopy for identification of metabolites in biologic samples. Molecules 2020, 25, 4725. [CrossRef]

32. Almond, J.; Sugumaar, P.; Wenzel, M.N.; Hill, G.; Wallis, C. Determination of the carbonyl index of polyethylene and polypropylene using specified area under band methodology with ATR-FTIR spectroscopy. e-Polymers 2020, 20, 369-381. [CrossRef]

33. Fritzsche, A.; Ritschel, T.; Schneider, L.; Totsche, K.U. Identification and quantification of single constituents in groundwater with Fourier-transform infrared spectroscopy and Positive Matrix Factorization. Vib. Spectrosc. 2019, 100, 152-158. [CrossRef]

34. Sonawane, S.S.; Chhajed, S.S.; Attar, S.S.; Kshirsagar, S.J. An approach to select linear regression model in bioanalytical method validation. J. Anal. Sci. Technol. 2019, 10, 1. [CrossRef]

35. Akhgar, C.K.; Ramer, G.; Żbik, M.; Trajnerowicz, A.; Pawluczyk, J.; Schwaighofer, A.; Lendl, B. The next generation of IR spectroscopy: EC-QCL-based Mid-IR transmission spectroscopy of proteins with balanced detection. Anal. Chem. 2020, 92, 9901-9907. [CrossRef]

36. Cowger, W.; Gray, A.; Christiansen, S.H.; DeFrond, H.; Deshpande, A.D.; Hemabessiere, L.; Lee, E.; Mill, L.; Munno, K.; Ossmann, B.E.; et al. Critical review of processing and classification techniques for images and spectra in microplastic research. Appl. Spectrosc. 2020, 74, 989-1010. [CrossRef] [PubMed]

37. Yapar, E.A.; Özdemirhan, M.E. An overview on pharmacopoeias in the world and monograph elaboration techniques. Univers. J. Pharm. Res. 2020, 5, 57-64. [CrossRef]

38. Directorate General of the Pharmaceuticals and Medical Devices. Indonesian Pharmacopoeia-Issue 6; Health Ministry of the Republic of Indonesia: Jakarta, Indonesia, 2020.

39. Belouafa, S.; Habti, F.; Benhar, S.; Belafkih, B.; Tayane, S.; Hamdouch, S.; Bennamara, A.; Abourriche, A. Statistical tools and approaches to validate analytical methods: Methodology and practical examples. Int. J. Metrol. Qual. Eng. 2017, 8, 9. [CrossRef]

40. Marson, B.; Concentino, V.; Junkert, A.; Fachi, M.; Vilhena, R.; Pontarolo, R. Validation of analytical methods in a pharmaceutical quality system-An overview focused on HPLC methods. Química Nova 2020, 43, 1190-1203. [CrossRef]

41. Gavali, K.V.; Shaikh, A.A.; Tamboli, A.M.; Khan, N.I. Development and validation of UV method for the simultaneous estimation of racecadotril and ofloxacin in bulk drugs and marketed formulation. World J. Pharm. Res. 2020, 1, 792-802. [CrossRef] 
42. Aasodi, R.R.; Murugan, V.; Premakumari, K.B. Application of total error concept in the analytical method validation for the assay of essential amino acids by precolumn derivatization. J. Appl. Pharm. Sci. 2020, 10, 31-42. [CrossRef]

43. Jampilek, J.; Dolowy, M.; Pyka-Pajak, A. Estimating limits of detection and quantification of ibuprofen by TLC-Densitometry at different chromatographic conditions. Processes 2020, 8, 919. [CrossRef]

44. Stoilova, N.; Boneva, I.; Yaneva, S. Development and validation of analytical methods for monitoring program for control of residues of pharmacologically active substances in tissues with animal origin. Pharma Innov. 2020, 9, $29-35$.

45. Ekasari, W.; Widiyastuti, Y.; Subositi, D.; Hamsidi, R.; Widyawaruyanti, A.; Basuki, S.; Setyawan, D. Determination of cassiarin a level of Cassia siamea leaf obtained from various regions in Indonesia using the TLC-densitometry method. Sci. World J. 2020, 2020, 7367836. [CrossRef]

46. Lavanya, C.G.; Ravisankar, P.; Akhil, K.G.; Mounika, K.; Srinivasa, B.P. Analytical method validation parameters-An updated review. Int. J. Pharm. Sci. Rev. Res. 2020, 61, 1-7.

47. Bui, V.T.; Doan, C.S.; Tong, T.T.V.; Le, D.C. Development and validation of a simple, green infrared spectroscopic method for quantitation of sildenafil citrate in siloflam tablets of unknown manufacturing formula. J. Anal. Methods Chem. 2021, 2021, 6616728. [CrossRef]

48. Kotadiya, M.; Khristi, A. Quantitative determination and validation of teneligliptine hydrobromide hydrate using FTIR spectroscopy. J. Chem. Pharm. Res. 2017, 9, 109-114.

49. Singh, A.; Baghel, U.S.; Sinha, M.; Ashawat, M.S. Quantitative analysis of rosuvastatin calcium in bulk and solid pharmaceutical dosage forms using green and rapid fourier-transform infrared spectroscopic method. Indian J. Pharm. Sci. 2020, 82, 632-639. [CrossRef]

50. Sheeja, V.K.; Swapna, A.S. Method development and validation for the simultaneous estimation of clonazepam and paroxetine in combined dosage form using FT-IR. Asian J. Res. Chem. 2020, 13, 12-14. [CrossRef]

51. Judeh, A.A.; Sarief, A.; Umar, Y.; Ashwaq, O.; Haque, S.M. Development, computational studies and validation of spectrophotometric method of metformin hydrochloride in pharmaceutical formulations. J. Chil. Chem. Soc. 2020, 65, 4895-4899. [CrossRef]

52. Naz, A.; Tabish, I.; Naseer, A.; Siddiqi, A.Z.; Siddiqui, F.A.; Mirza, A.Z. Green chemistry approach: Method development and validation for identification and quantification of entecavir using FT-IR in bulk and pharmaceutical dosage form. Future J. Pharm. Sci. 2021, 7, 75. [CrossRef]

53. Chikanbanjar, N.; Semwal, N.U.J. A review article on analytical method validation. J. Pharm. Innov. 2020, 1, 48-58.

54. Almeida, J.; Bezerra, M.; Markl, D.; Berghaus, A.; Borman, P.; Schlindwein, W. Development and validation of an in-line API quantification method using AQbD principles based on UV-Vis spectroscopy to monitor and optimise continuous hot melt extrusion process. Pharmaceutics 2020, 12, 150. [CrossRef] [PubMed] 